\title{
A cross-cultural study on noise problems
}

\author{
Seiichiro Namba, ${ }^{*}$ Sonoko Kuwano, ${ }^{*}$ and August Schick** \\ *College of General Education, Osaka University, \\ 1-1, Machikaneyama, Toyonaka, 560 Japan \\ ** Oldenburg University, \\ Postfach 2503, D-2900 Oldenburg, F. R. Germany
}

(Received 7 November 1985)

\begin{abstract}
Cross-cultural surveys on neighborhood noise problems were conducted in Japan, Germany and England in 1980 and 1983. The main findings are as follows: (1) Some differences were found between Japan and Germany in sounds which residents were aware of or annoyed by. (2) In both countries the use of loudspeakers was accepted for conveying information necessary to the respondents. (3) German respondents seemed to find it more difficult to become habituated to noise, and to be less tolerant of being annoyed by noise from neighbors. (4) When annoyed by noise from neighbors, German respondents tended to take more direct actions. They also chose more direct countermeasures against noise. (5) In the opinions concerning neighborhood noise problems, Japanese. respondents had more critical attitudes. (6) The affective meanings of some terms related to noise (e.g. "loudness" and "noise") were different in different languages. The differences found in these surveys seem to derive from the cultural backgrounds of the countries.
\end{abstract}

PACS number: 43. 50. $-\mathrm{x}$

\section{INTRODUCTION}

Noise is defined as "unwanted sound." ") This is basically a psychological definition. Whether a sound is "unwanted" or not depends on the persons exposed to it, so the reaction is different with different individuals and different situations. ${ }^{2)}$ A person's behavior is determined by his frame of reference, which is created by his personality, and the society he belongs to. ${ }^{3)}$ It is probable that sounds which are acceptable in some societies may be unwanted sounds in other societies. In a society where people are tolerant of noise they will not take any special care not to make noise.

Sound sources which cause annoyance between neighbors may be different in different societies. In the case of neighborhood noise, the social and personal importance of the sound source may affect whether the sound is acceptable or not, regardless of the sound level. Therefore it is essential to find the individual and social factors which determine the unwantedness of sounds in order to understand noise problems.

Organizations such as ISO and IEC have attempted to reach international agreement on the standardization of the definition of noise and its measurement. However, if this is done without considering the noise situation and its background in each country, it may cause so-called "cultural friction." Moreover, the connotative meanings of languages cannot fully be understood from dictionaries. "Cognitive category" is different in different languages., ${ }^{4}$ ) To take an example from visual perception, a certain color which is perceived as being "brown" by Japanese may be categorized as "orange" in some western countries. Therefore, in order to reach understanding for the international standardization of matters connected with noise, it is necessary to understand the connotative meanings of the terms related to noise in the language of each country. 
Cross-cultural study of noise problems is therefore important. A successful study of this sort can provide us with very useful information. When there is close agreement in the findings from different countries, general observations will be established or confirmed. When there are discrepancies, they may be clues to the social factors which affect the formation of attitudes, and thus an approach to cross-cultural understanding.

In order to make reliable generalizations, there are some conditions which must be fulfilled. Needless to say, the equivalency of the terms in the various languages used for questionnaires is important. If the connotative meanings of the terms used are not equivalent, it is almost impossible to distinguish whether differences in the results are due to differences between the countries or between the questionnaires.

In undertaking a cross-cultural study, special care must be taken. After considering the difficulties, we have designed a questionnaire on noise problems and conducted a cross-cultural survey.

\section{QUESTIONNAIRE SURVEY}

\subsection{First Survey ${ }^{6,7)}$}

The first survey was conducted in Japan, Germany and England in 1980. The respondents were: 434 students in Japan, 457 in Germany, and 110 in England. The questionnaire consisted of the following items: (a) negative attitudes to noise, (b) countermeasures against noise, (c) measurement of meaning of concepts, using semantic differential, and (d) face sheet.

\subsection{Second Survey ${ }^{8,9)}$}

The second survey was conducted in Japan and Germany in 1983. The respondents were: 375 in Japan and 296 in Germany. They were chosen from the residents of apartment houses, since the living conditions of apartment houses were judged to be similar in both countries. The questionnaire consisted of the following items: (a) sounds which respondents were aware of or annoyed by, (b) actions taken against neighborhood noise, (c) experience of making complaints directly to neighbors, (d) living conditions, (e) opinions on the need for the use of loudspeakers in public places, (f) negative attitudes to noise (same question as used in the first survey), (g) comparison of degree of annoyance caused by noise generated by the respondents themselves and by neighbors, (h) sensitivity to noise, and (i) face sheet.

\subsection{Back-translation ${ }^{10)}$}

The equivalency of the questionnaires, which were written in Japanese, German and English, was confirmed by a back-translation technique. That is, part of the original questionnaire was made in Japanese and the other part was made in German. After discussion conducted in English, Japanese, German, and English versions were completed. These German and English versions were translated into Japanese by other bilingual persons. Although there were some subtle discrepancies, the agreement of this back-translated Japanese version and the original Japanese version confirmed the equivalency of the questionnaires.

\section{RESULTS AND DISCUSSION}

\subsection{Sounds from Neighbors}

Not all the sounds audible from neighbors are annoying. The relation between audible sounds and annoying sounds is shown in Fig. 1. The ratio of annoying sounds to audible sounds is higher in Germany than in Japan. When this ratio is different in neighboring homes, neighborhood noise problems may occur. Though many noise sources are audible in both countries, in Germany they tend to be solidborne sounds, and in Japan air-borne sounds.

\subsection{Announcements Using Loudspeakers}

Recently in Japan there have been many complaints against the use of loudspeakers for announcements in public places (e.g. Fig. 1 No. 30). As shown in Fig. 2, the respondents of both countries accepted use of the loudspeakers for conveying information necessary to them, though the use for advertisements is considered unnecessary. There was a difference between the two countries in the use of loudspeakers in some places. The use of loudspeakers at schools seemed less acceptable in Germany, and at swimming pools in Japan.

\subsection{Sensitivity to Noise}

If sensitivity to noise is low in all residents in a neighborhood, neighborhood noise problems will not occur. However, the problems become very serious when persons with high-sensitivity and lowsensitivity live close to each other. As shown in Fig. 3, German respondents seemed to find it more 


\section{S. NAMBA et al.: A CROSS-CULTURAL STUDY ON NOISE PROBLEMS}
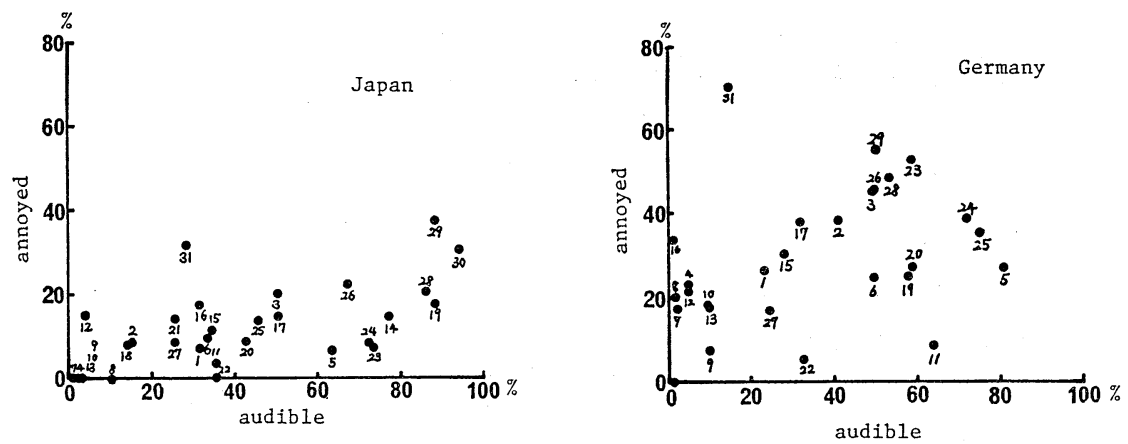

Fig. 1 Relation between audible sounds and annoying sounds. It is noted that the ratio of annoying sounds to audible sounds is higher in Germany than in Japan. 1. television, 2. radio, 3. stereo, 4. sound film projector or video recorder, 5. bathroom or toilet, 6. washing machine or drier, 7. hairdrier, 8. ventilator, 9. electric machines for cooking, 10. dishwashing machine, 11. vacuum cleaner, 12. sewing machine, 13. typewriter, 14. piano, 15. other musical instruments, 16. air-conditioner, 17. pet animals, 18. indoor games, 19. children and young people, 20. voices of the neighbors, 21. "KARAOKE," 22. telephone, 23. banging doors, 24 . noises in the communal hall, stairways and lifts, 25. handicrafts, 26. noises from the floor above, 27. moving furniture, 28. autos of the neighbors, 29. mopeds or motorcycles, 30. loudspeaker for selling, 31. other noises.

At the station

a) Announcements of the train's arrival

b) Announcements of the destination and stoppage of the standing train

c) Singals for starting

d) Various cautions

(e.g. no smoking, to step back behind the safety line)

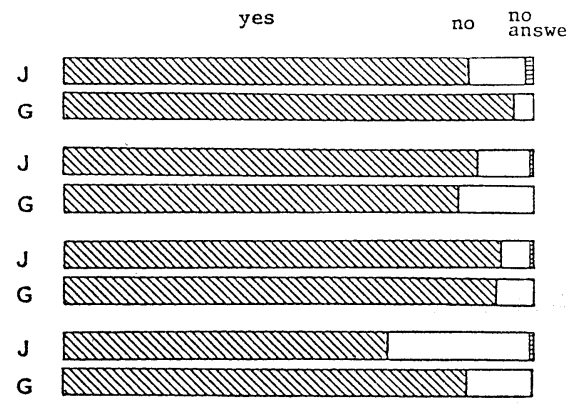

At the playgrounds or pools

a) Announcements of the players and the results

b) Advertisements

c) Various cautions

(e.g. not to jump into the pool from the side)

d) Musical performances

e) Introduction of the players

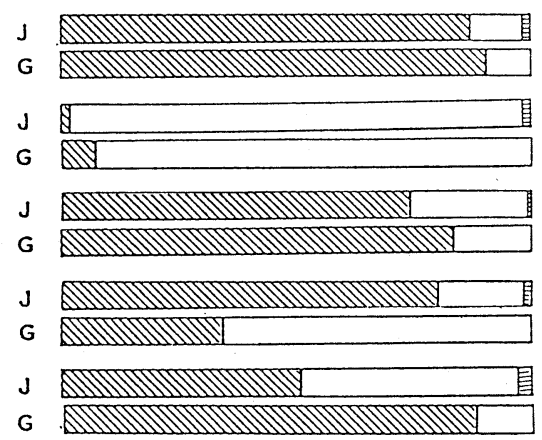

On the street, etc.

d) Use of loudspeakers at school

(e.g. morning meeting, announcements, athletic meeting)

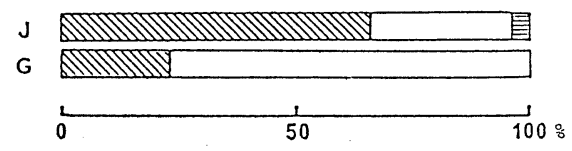

Fig. 2 Opinions concerning the use of loudspeakers in public places. The respondents of both countries accepted use of the loudspeakers for conveying information necessary to them. 


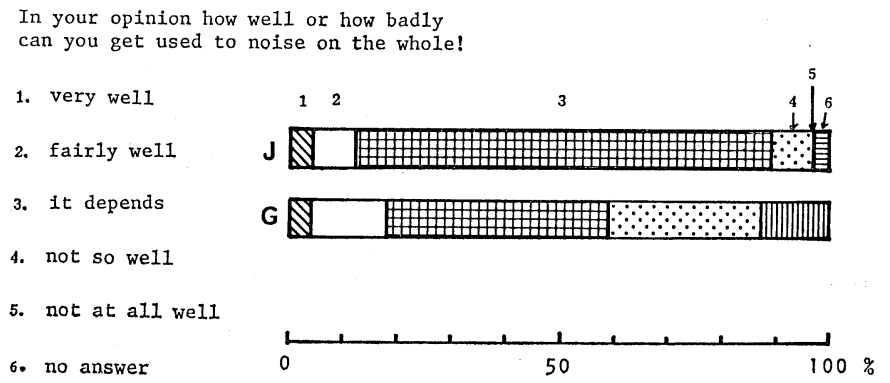

Fig. 3 Sensitivity to noise. German respondents seem to find it more difficult to become habituated to noise than Japanese respondents.

How annoying are the following noises to you? Please check off

your answer.

sound of screeching train

car horns in the street tooting in chorus

rustling paper

loud sound from radio and television

constant banging of doors

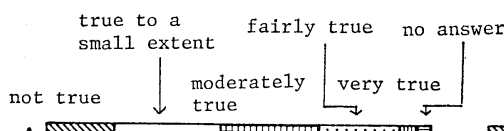

B $\$$ B
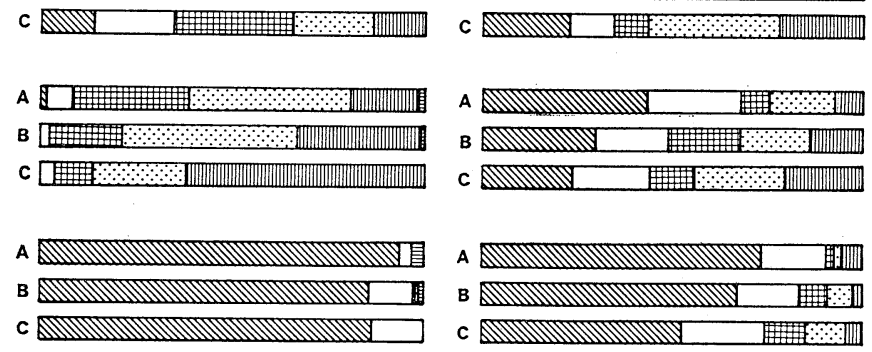

A $\mathrm{M}$ B ${ }_{2}$ c $\$$ L
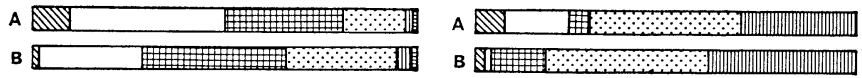

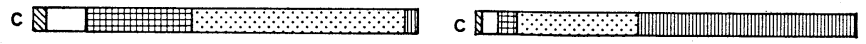

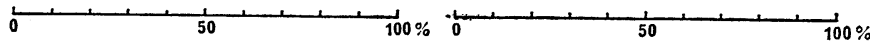

A : I can get used to noise very well. $\quad$ B : It depends on the case. C : I can not get used to noise so well.
I can get used to noise fairly well.

Fig. 4 Annoyance to various sound sources (Results of cross-analysis using sensitivity to noise as a key item). In both countries, respondents who have difficulty in becoming habituated to noise seem to be more sensitive to noise.

Fig. 6 Countermeasures against neighborhood noise (Results of the second survey). It is noticed that German respondents chose more direct countermeasures than Japanese respondents. 
Fig. 5 Countermeasures against neighborhood noise (Results of the first survey). In Germany and Japan arrangement by community rules is considered the most desirable countermeasure. Severe legal regulation was not desired in any of these countries.

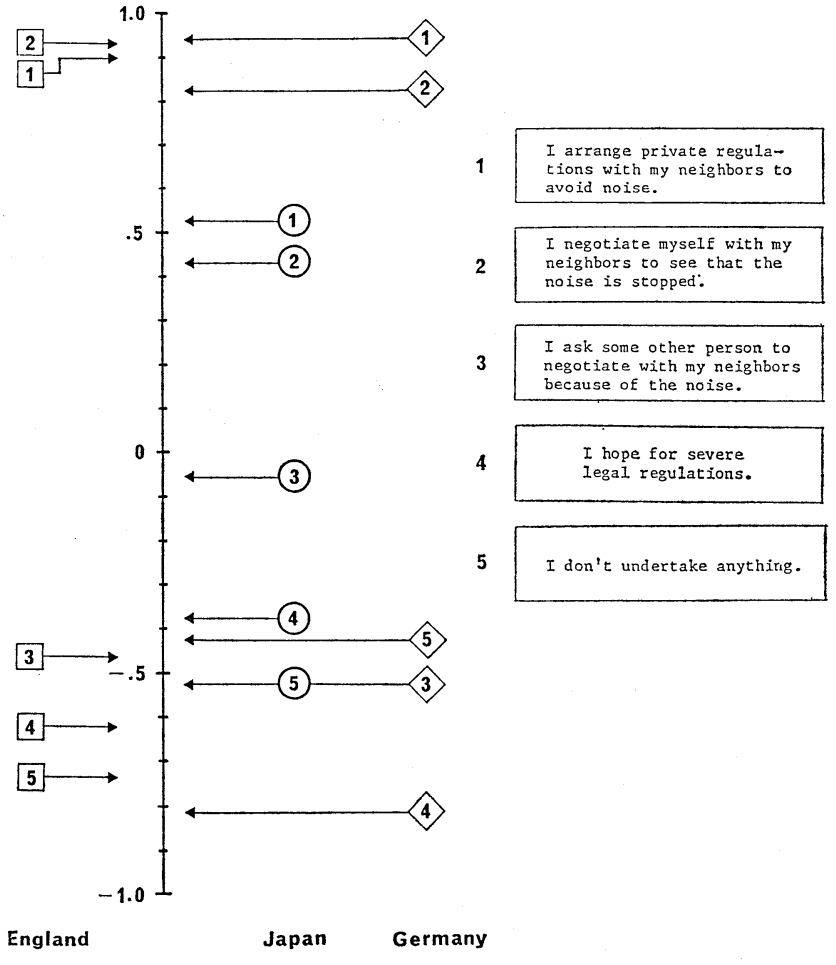

If you are annoyed by noises from your neighbors, which of the following measures appear to you personally to be sensible and practicable?

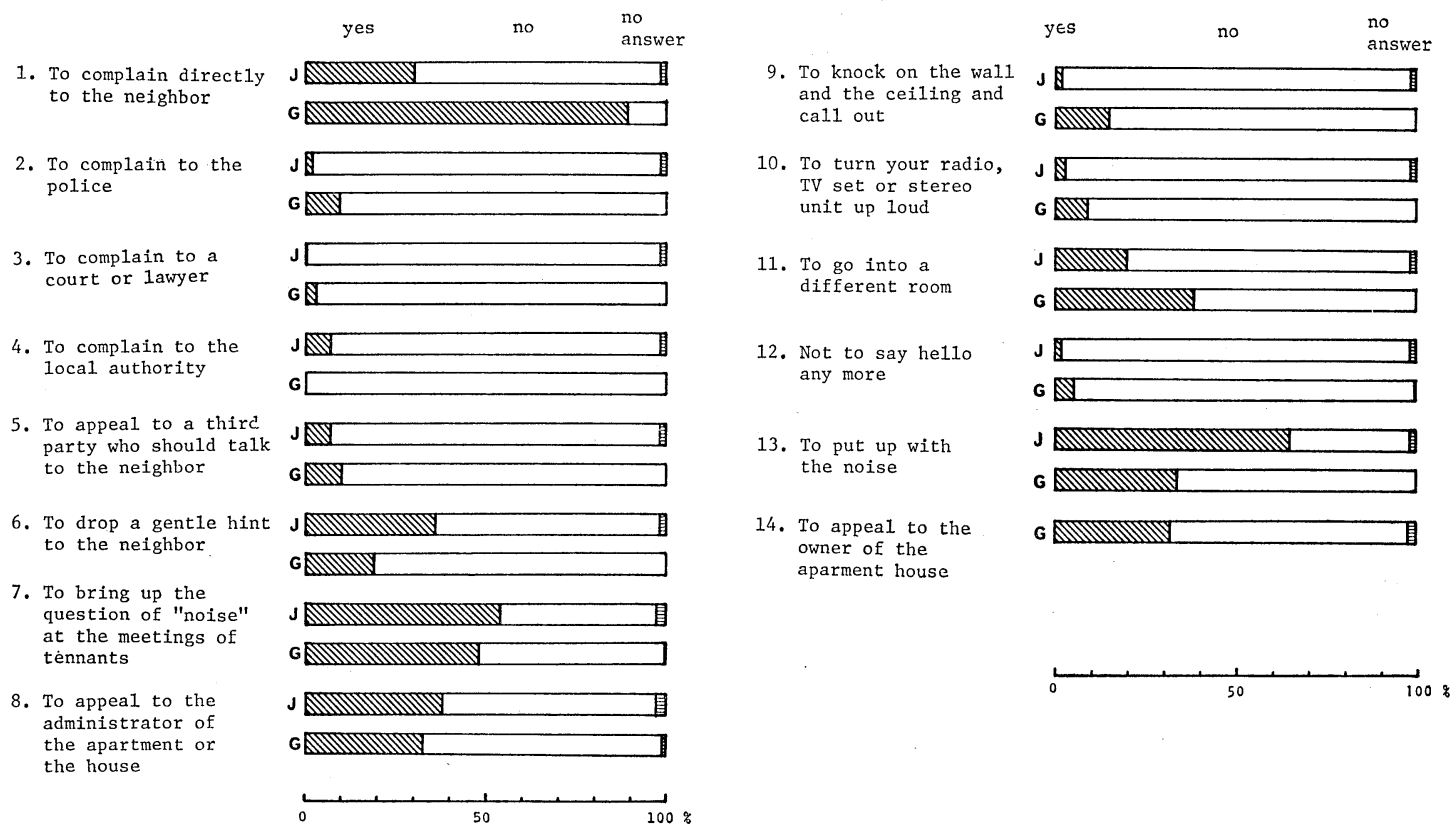


Have you ever appealed directly to your neighbors because they are noisy?
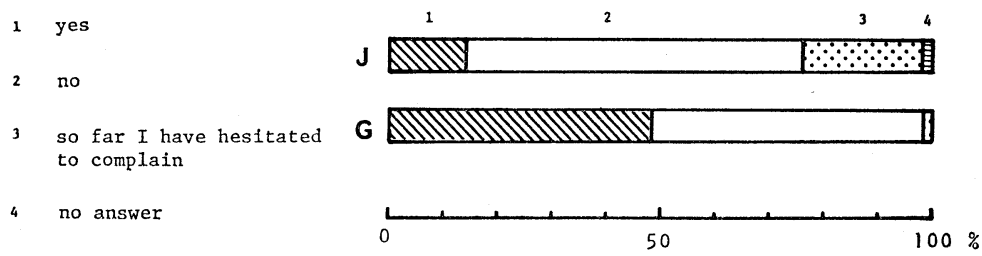

Fig. 7 Experience of complaining directly to neighbors. It is noticeable that German respondents had much more experience than Japanese respondents.

1. If my neighbors make noise, I tolerate it because I also make noise myself occasionally.

2. My neighbor's noise is part of my daily life; therefore my neighbor and $I$ are happy about the noise.

3. I do not tolerate, being annoyed by my neighbor's noise.

4. My neighbors and I make noise ourselves! Why should we, therefore, make the least possible noise in our daily life?

5. I should make as little noise as possible, so as not to bother my neighbors.

6. If my neighbors complain about my noise, then I should immediately stop the noise.

7. If my neighbors complain about the noise from my home, then I say, "we both make noise in our dally life and therefore both of us must also endure it". (a: 1980)

(b: 1983)
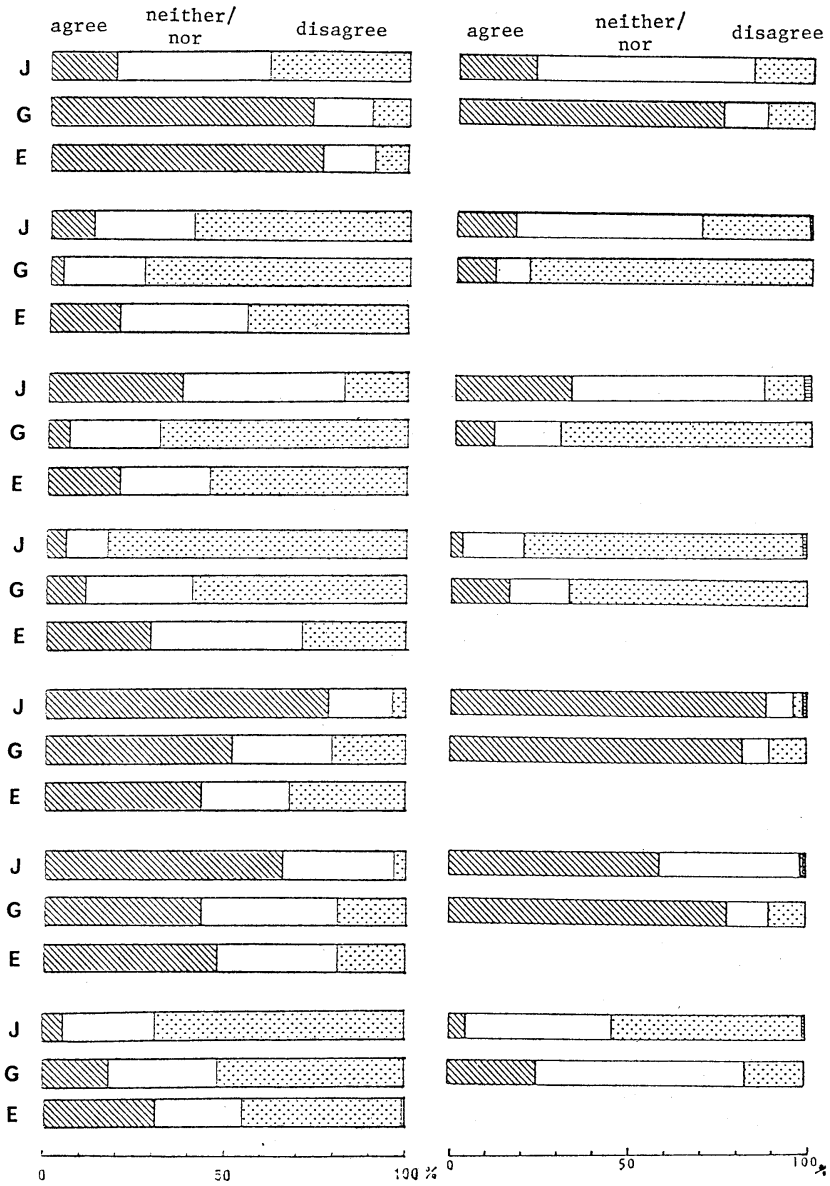

Fig. 8 Opinions concerning neighborhood noise problems (a: results of first survey, b: results of second survey). Japanese respondents were found to have more critical attitudes to noise problems than German and English respondents. 


\section{S. NAMBA et al.: A CROSS-CULTURAL STUDY ON NOISE PROBLEMS}

difficult to become habituated to noise than Japanese respondents. In both countries, respondents who have difficulty in becoming habituated to noise seemed to be more sensitive to noise (Fig. 4).

\subsection{Countermeasures against Noise}

Countermeasures against noise were examined using the method of paired comparison in the first survey. The results are shown in Fig. 5. In Germany and Japan, arrangement by community rules is considered the most desirable countermeasure. On the other hand, in England direct negotiation between neighbors was ranked first by a small margin. Severe legal regulation was not desired in any of these countries.

The results of the second survey are shown in Fig. 6. German respondents chose more direct countermeasures than Japanese respondents. In particular, the percentage choosing "to complain directly to their neighbors" is much higher among German respondents. On the other hand, choosing "to endure" is highly favored by Japanese respondents.

In terms of action taken, German respondents had much more experience of complaining directly to their neighbors (Fig. 7).

\subsection{Negative Attitude to Noise}

The opinions of respondents concerning neighborhood noise problems were covered in both the first and second surveys. As shown in Fig. 8 (a), (b), in both surveys similar results were found, indicating that Japanese respondents have more critical attitudes to noise problems than German and English respondents, though the difference between Japan and Germany was smaller in the results of the second survey.

\subsection{Meaning of Concepts}

The meaning of nine concepts was measured using semantic differential in the first survey. The concepts were: loudness, noisiness, annoyance, noise, environment, government, science, technology, and pop music. Some examples of the semantic profiles are shown in Figs. 9 12. There is an interesting difference between Japan and the other countries in the profiles of "loudness." Japanese "loudness" is quite neutral, but both German and English "loudness" has negative connotations. The profiles of German and English "loudness" are similar to those of "annoyance." The profiles of "annoyance" show good agreement in the three countries. The profiles of English and Japanese "noisiness" show a quite similar pattern to that of "annoyance." There is no term equivalent to "noisiness" in German. English "noise" is rather neutral compared with Japanese and German "noise." This may be because English "noise" has two meanings: one is "inharmonic sound" and the other is "unwanted sound."

In Japan the reliability of the results of this questionnaire was confirmed by conducting the same questionnaire survey using different groups of subjects since 1981. Examples of the results are shown in Figs. 13 16. The figures clearly show good agreement between the six surveys. Reliability was also confirmed by the German survey.

In these surveys conducted since 1981, another concept "OTO-NO-OKISA," which means "loudness of sound," was included in the measurement of semantic differential, since "OKISA", i.e. "loudness" in Japanese, means both "loudness" and "size." The result is shown in Fig. 17. It was confirmed that "loudness" has neutral meaning in Japan, even when it is limited to "loudness of sound."

The coefficient of correlation between the profiles is shown in Table 1. High coefficient of correlation was obtained between German and English profiles, whereas the coefficient of correlation between Japan and the other countries was lower. This may be due to the difference of origin of the Japanese language from that of the other two countries.

The results of factor analysis are shown in Fig. 18 (a) and (b). There is close agreement in adjective scales, but wide divergence in the concepts.

Table 1 Coefficient of correlation.

\begin{tabular}{lccc}
\hline \multicolumn{1}{c}{ Concept } & J-G & J-E & G-E \\
\hline Pop music & 0.469 & 0.493 & 0.875 \\
Technology & 0.454 & 0.610 & 0.956 \\
Science & 0.667 & 0.848 & 0.915 \\
Government & 0.527 & 0.610 & 0.949 \\
Environment & 0.077 & 0.849 & 0.505 \\
Annoyance & 0.979 & 0.961 & 0.985 \\
Noise & 0.977 & 0.890 & 0.958 \\
Loudness & 0.049 & 0.238 & 0.951 \\
Noisiness & & 0.965 & \\
\hline
\end{tabular}




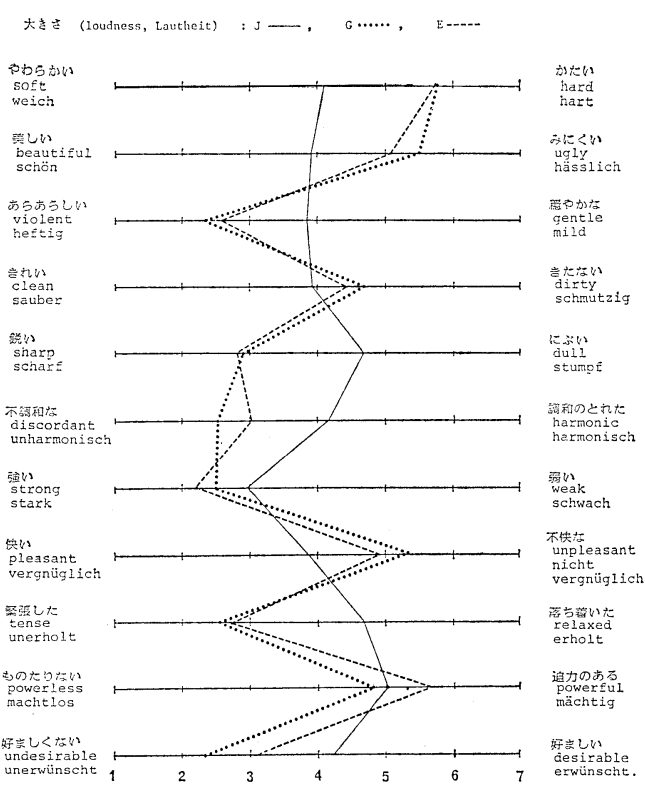

Fig. 9 Semantic profiles of "loudness." There is an interesting difference between Japan and the other two countries in the profiles of "loudness." Japanese "loudness" is quite neutral, but both German and English "loudness" has negative connotations.

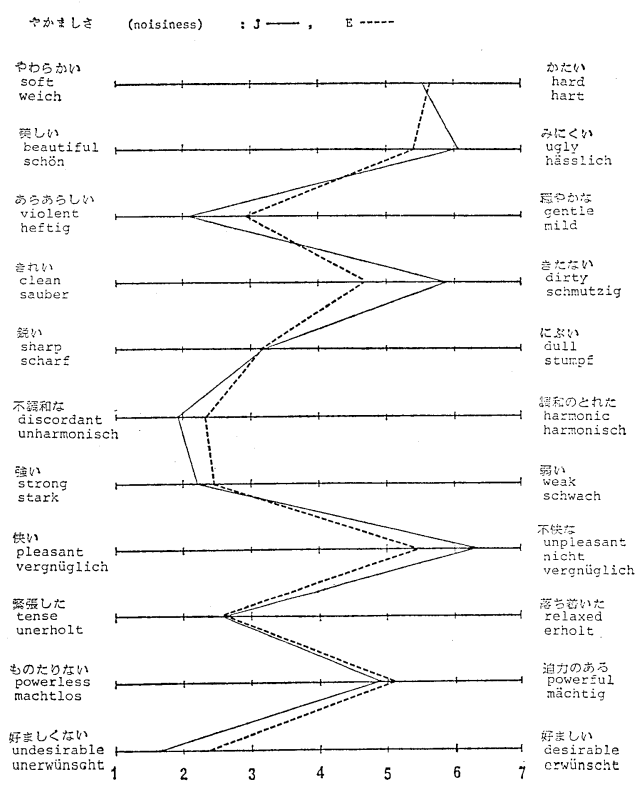

Fig. 11 Semantic profiles of "noisiness." The profiles of English and Japanese "noisiness" show a quite similar pattern to that of "annoyance." There is no term equivalent to "noisiness" in German.

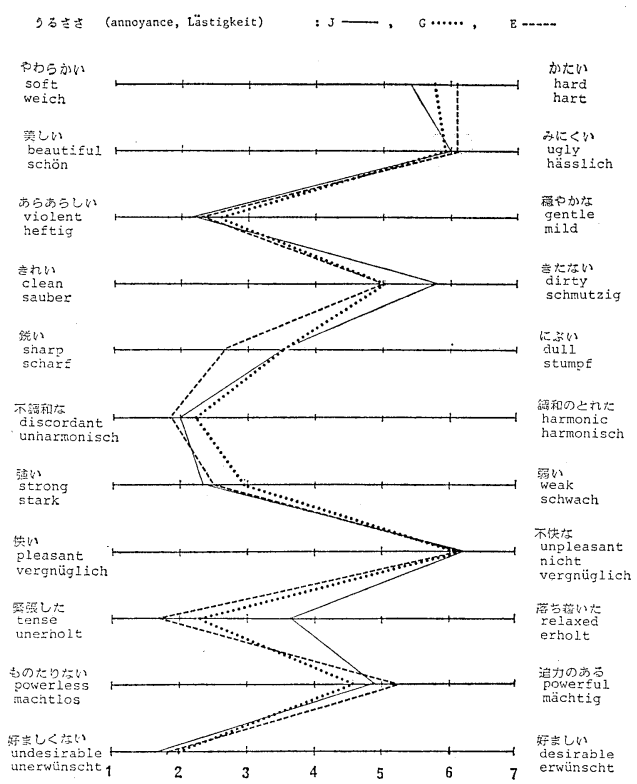

Fig. 10 Semantic profiles of "annoyance." The profiles of "annoyance" show good agreement in the three countries.

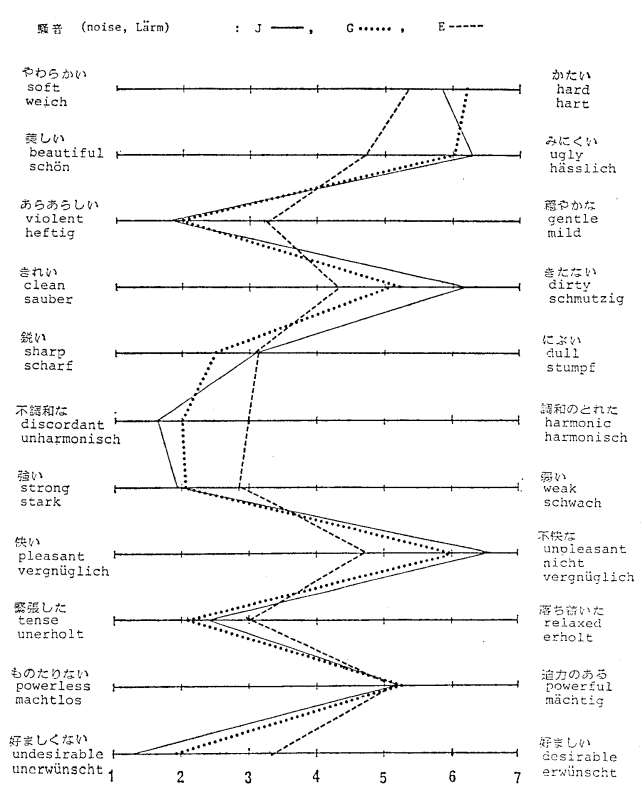

Fig. 12 Semantic profiles of "noise." English "noise" is rather neutral compared with Japanese and German "noise." 


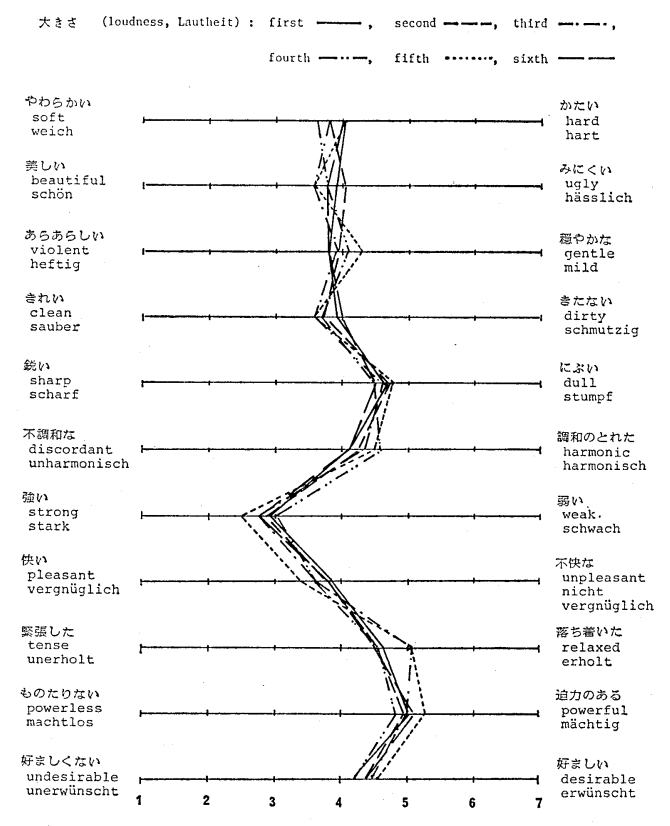

Fig. 13 Semantic profiles of Japanese "loudness" obtained in six different surveys. Good agreement among six surveys confirms the reliability of the surveys.

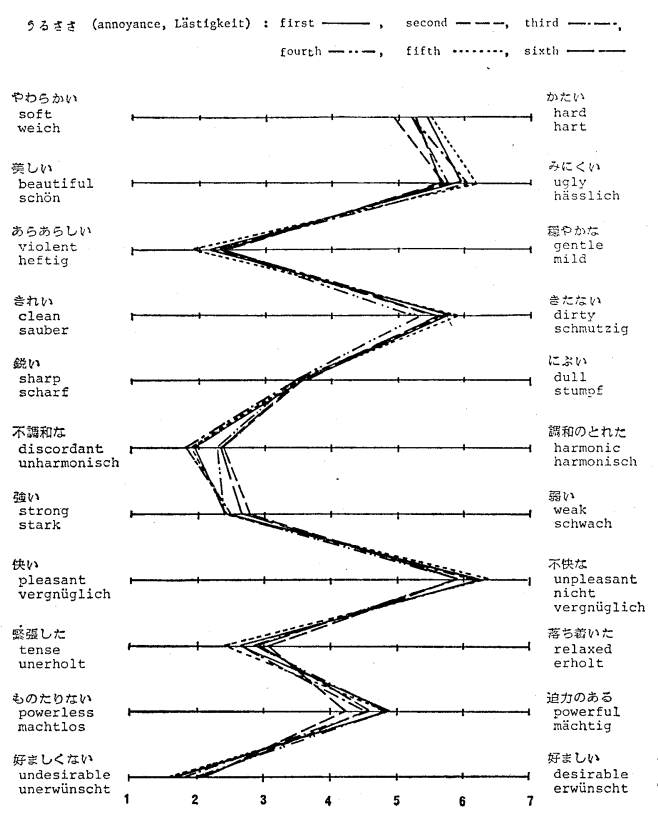

Fig. 15 Semantic profiles of Japanese "annoyance" obtained in six different surveys.

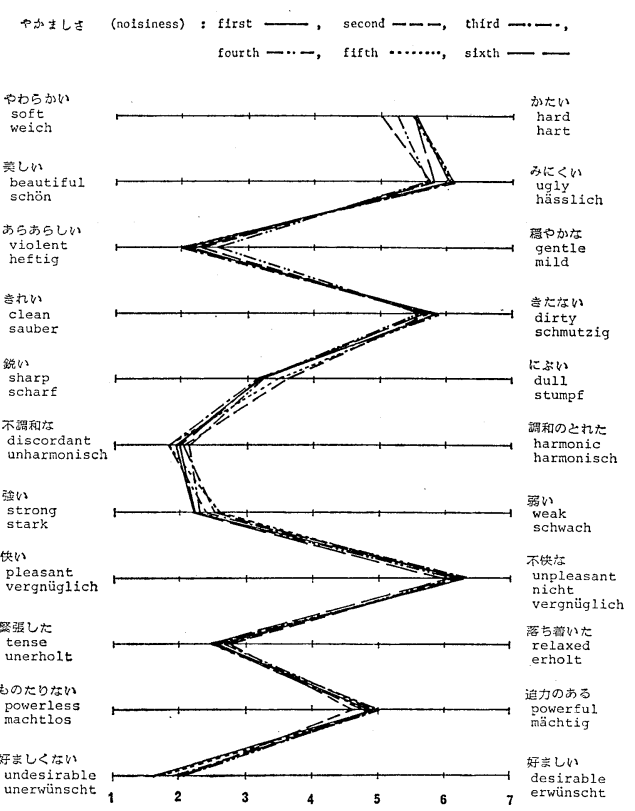

Fig. 14 Semantic profiles of Japanese "noisiness" obtained in six different surveys.

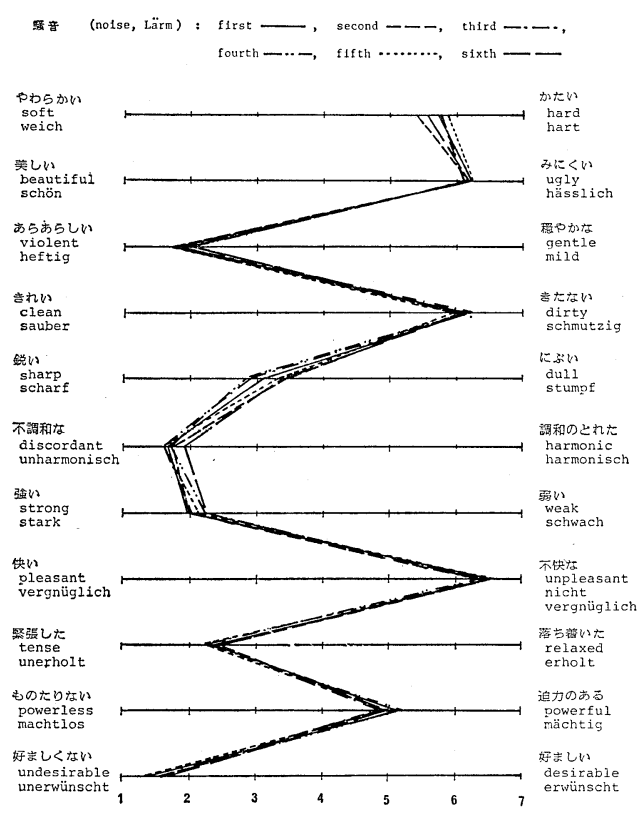

Fig. 16 Semantic profiles of Japanese "noise" obtained in six different surveys. 


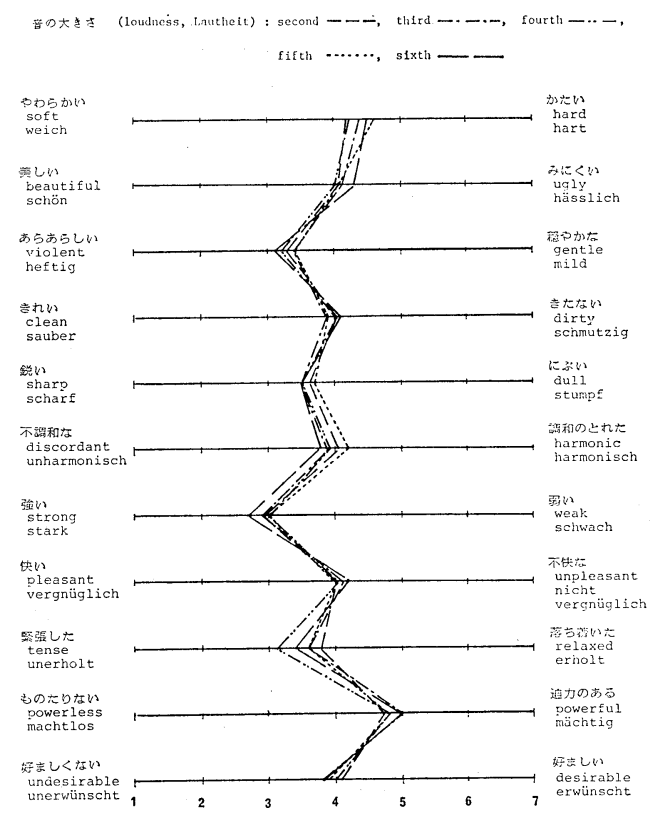

Fig. 17 Semantic profiles of Japanese "OTO-NOOKISA" (loudness of sound) obtained in the second to sixth surveys. It was confirmed that "loudness" has neutral meaning in Japan, even when it is limited to "loudness of sound."

\section{CONCLUSION}

1) Cross-cultural surveys of neighborhood noise problems were conducted in Japan, Germany and England in 1980 and 1983. The number of samples was limited in the three countries. However, as shown in Figs. 13 17, good agreement was found between the results obtained from different samples of the surveys conducted in different years. This fact suggests that the surveys are reliable.

2) From the results of the second survey, some differences were found between Japan and Germany in sounds which residents were aware of or annoyed by. This fact suggests that natural features or patterns of everyday life may affect whether sounds become "unwanted sounds" or not. Moreover, sound sources which cause annoyance may differ according to the construction of buildings.

3) In both countries the use of loudspeakers was accepted for conveying information necessary to the respondents, and the use for advertisements was considered unnecessary. The German respondents were more tolerant of it at swimming pools and less at schools than Japanese respondents. This suggests that acceptable sounds are different in different socie-

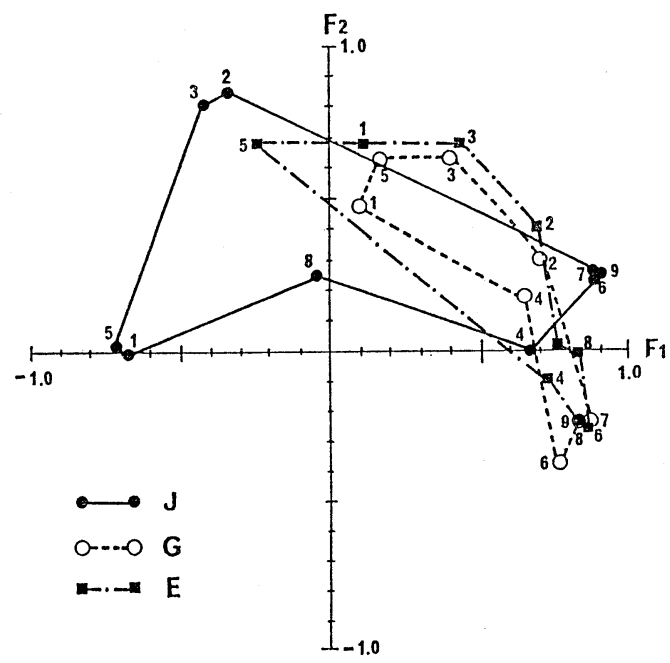

(b) Concept

1. pop music, 2. technology, 3. science, 4. government, 5. environment, 6. annoyance, 7. noise, 8. loudness, 9. noisiness.

1. soft, 2. beautiful, 3. violent, 4. clean, 5. sharp, 6. discordant, 7. strong, 8 . pleasant, 9. tense, 10. powerless, 11. desirable.

Fig. 18 Results of factor analysis. There is close agreement in adjective scales (a), but wide divergence in the concepts (b). 


\section{S. NAMBA et al:: A CROSS-CULTURAL STUDY ON NOISE PROBLEMS}

ties.

4) Sensitivity to noise was found to be different between Japanese and German respondents. In particular, German respondents seemed intolerant of rustling papers. Moreover, they seemed to find it more difficult to become habituated to noise, and to be less tolerant of being annoyed by noise from neighbors than Japanese respondents.

5) When annoyed by noise from neighbors, German respondents tended to take direct action involving their neighbors. On the other hand, Japanese respondents tended to hesitate to take direct action and endure noise in fear of harming human relations.

6) In the opinions of respondents concerning neighborhood noise problems, German respondents were more tolerant than Japanese. It is interesting that there was a gap between opinions and actions taken in both countries.

7) It was found that the affective meanings of some terms related to noise were different in different languages even though they have similar meanings in dictionaries. English "noise" and Japanese "loudness" were found to have neutral meaning, but these terms had negative meaning in the other countries. Generally, there was a close agreement between the meanings of German and English terms, but Japanese tended to have different meanings from the other languages. This fact suggests that the distance between terms is different in different linguistic systems. Therefore the terms used in international standards must be carefully defined. Similar surveys may be necessary not only of terms but of sentences. It may be difficult or almost impossible to get perfect equivalency between terms or sentences used in different countries, but we should try to do our best to lessen the gap between them.

8) From these cross-cultural surveys, it was found that there are great similarities, and some interesting differences, between the three countries. These differences seem to derive from the cultural backgrounds of the countries. In order to understand each other, further study of this sort is desirable.

\section{ACKNOWLEDGEMENTS}

The authors are grateful to Dr. J. R. Thomas at Warwick University for his kind cooperation in doing a survey in England, and Dr. J. Igarashi at Kobayashi Institute for Physical Research, Professor O. Kitamura at Osaka University for Arts and Dr. Y. Osada at Institute of Public Health for their helpful advice.

A part of this study was supported by a grant of Deutscher Akademischer Austauschdienst, Deutsche Forschungsgemeinschaft, and Japan Society for the Promotion of Science.

\section{REFERENCES}

1) S. Morita, Noise and Its Prevention (Ohm-sha, Tokyo, 1961) (in Japanese), p. 1.

2) S. Namba, S. Kuwano, T. Nakamura, and T. Kato, "A questionnaire survey on community noise," J. Acoust. Soc. Jpn. 34, 592-599 (1978) (in Japanese with English abstract).

3) K. Yamamoto (Ed.), Living Surroundings and Stress (Kakiuchi-Shuppan, Tokyo, 1985) (in Japanese), p. 20.

4) T. Shibata and H. Fujii, Introduction to English: A Re-Examination (Nan-undo, Tokyo, 1985) (in Japanese), p. 135.

5) Y. Uno, K. Sawaki, K. Suzuki, K. Tsurumi, K. Toba, and K. Nomoto, Mechanism of Cultural Friction-On the International Refraction Theory-. (Science-sha, Tokyo, 1982) (in Japanese), p. 10.

6) S. Kuwano, S. Namba, and A. Schick, "Lautheit, Lärm und Lästigkeit im Kulturvergleich, "Fortschr. Akust. FASE 1 DAGA '82, 1127-1130 (1982).

7) J. R. Thomas, S. Namba, A. Schick, and S. Kuwano, "A cross-cultural study of noise annoyance. A comparison among Britain, Germany and Japan," 4th Int. Congr. on Noise as a Public Health Problem (1983).

8) A. Schick, S. Kuwano, and S. Namba, "Crosscultural examinations of noise in the neighborhood," Proc. Inter-Noise 84, 967-972 (1984).

9) S. Kuwano, S. Namba, and A. Schick, "Crosscultural survey on noise problems in apartment houses," Proc. Inter-noise 85, 937-940 (1985).

10) S. Namba, S. Kuwano, A. Schick, and J. R. Thomas, "A cross-cultural survey on the neighborhood annoyance caused by noise-The results of back-translation,” Rep. Spring Meet. Acoust. Soc. Jpn., 399400 (1983) (in Japanese). 